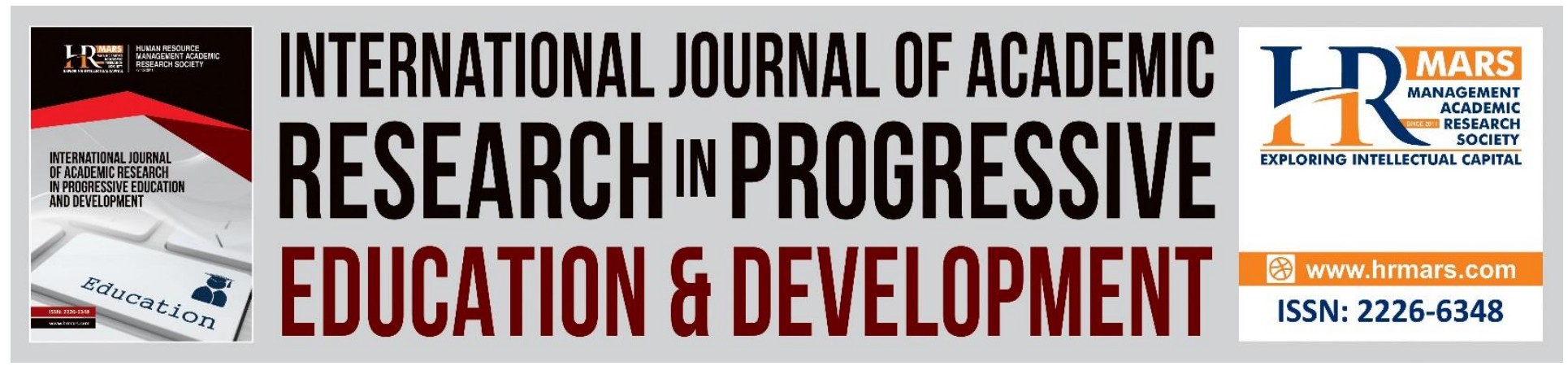

\title{
Comparing Back Lift Techniques in Front Foot Drive Batting Skills among Cricket Players
}

Norlena Salamuddin, Adam Zulkiflie

To Link this Article: http://dx.doi.org/10.6007/IJARPED/v8-i4/6784

DOI:10.6007/IJARPED/v8-i4/6784

Received: 12 November 2019, Revised: 30 November 2019, Accepted: 18 December 2019

Published Online: 30 December 2019

In-Text Citation: (Salamuddin \& Zulkiflie, 2019)

To Cite this Article: Salamuddin, N., \& Zulkiflie, A. (2019). Comparing Back Lift Techniques in Front Foot Drive Batting Skills among Cricket Players. International Journal of Academic Research in Progressive Education and Development, 8(4), 943-951.

Copyright: (C) 2019 The Author(s)

Published by Human Resource Management Academic Research Society (www.hrmars.com)

This article is published under the Creative Commons Attribution (CC BY 4.0) license. Anyone may reproduce, distribute, translate and create derivative works of this article (for both commercial and non-commercial purposes), subject to full attribution to the original publication and authors. The full terms of this license may be seen at: http://creativecommons.org/licences/by/4.0/legalcode

Vol. 8(4) 2019, Pg. 943 - 951

http://hrmars.com/index.php/pages/detail/IJARPED JOURNAL HOMEPAGE

Full Terms \& Conditions of access and use can be found at http://hrmars.com/index.php/pages/detail/publication-ethics 


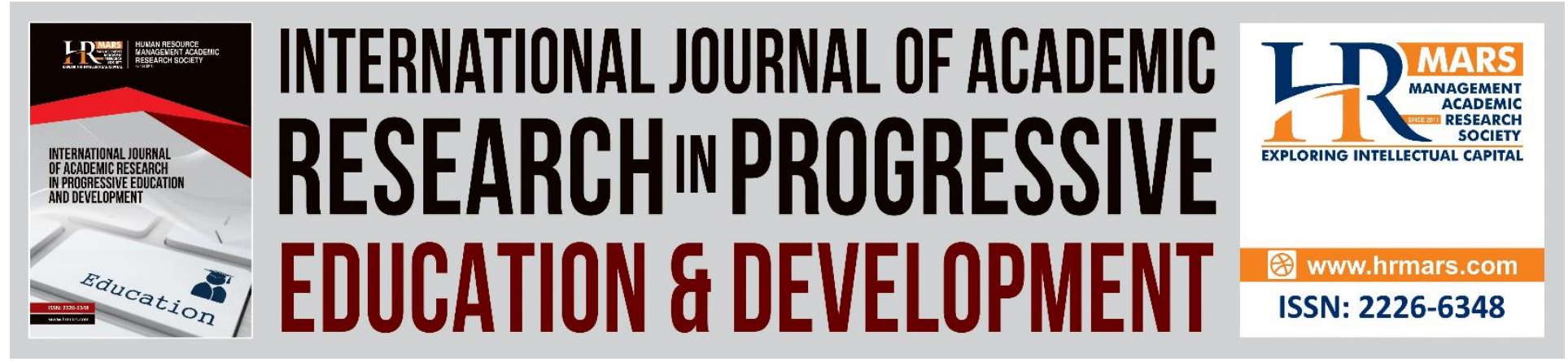

\title{
Comparing Back Lift Techniques in Front Foot Drive Batting Skills among Cricket Players
}

\author{
Norlena Salamuddin, Adam Zulkiflie \\ Universiti Kebangsaan Malaysia, Malaysia \\ Email: lena@ukm.edu.my
}

\begin{abstract}
The game of cricket emphasizes on hitting scoring shots which involved good batting skills. One of the basic skills of batting in cricket is the Front Foot Drive (FFD) which places the importance on the back lift techniques used. The aim of this study is to compare the accuracy, distance and reaction of time of FFD batting skill using two back lift techniques, namely Back lift Straight (BS) and Back lift Lateral (BL) techniques. Twenty-two male cricket players aged between 22 to 25 years old with an average playing years of were purposively selected as samples for this study. A bowling machine was used to ensure consistent speed and trajectory of ball so that distance, accuracy and reaction time of batting can be determined. Independent sample t-test were used to analyse the data obtained. The t-test analysis showed significant differences between BS and $B L$ techniques in testing the accuracy $(t=2.153, p=0.037)$. However, there were no significant difference between $B S$ and $B L$ techniques in distance of hitting and the time reaction of hitting. Results showed that different batting techniques is necessary for accuracy. In a close game accuracy to bat the ball out of reach of opponents is necessary. Thus, the results of this study suggest that coaches need to identify their players' batting techniques in order to strategize games especially against a good opponent. The findings also show that coaches need to be aware of their players batting style in order to be able to design training programs which are appropriate and effective for the players.
\end{abstract}

Keywords: Cricket, Batting Techniques, Back Lift Techniques, Front Foot Drive, Accuracy

\section{Introduction}

Technical factor is an important component in cricket. Good technique development will increase an athlete's capacity to consistently perform the correct skill during training as well as competition. Technical-based training focuses on batting and throwing techniques which helps in ensuring athletes' can perform the skills correctly and efficiently. Every playing position in cricket requires different techniques. There are various methods of hitting the ball such as Front Foot Drive, Cut shot, and Pull shot. Batting in cricket is regarded as a complex skill as it requires good motor skills dan physiology abilities to defend the wicket, hit the ball and look for opportunities to score as many runs as possible. A batter need to ensure that the ball is batted away from the fielders in order 
to gain as score. Optimal batting skills involve a variety of components including physiological, biomechanical and psychological factors (Stretch, Bartlett, \& Davids, 2000).

The Front Foot Drive (FFD), also commonly known as the straight drive, is a classic shot often used bt many batters. FFD shots were often employ with the aim of batting the ball with enough force to earn maximum runs but at the same time maintaining control over the ball. Result of a hit is often assessed by the linear speed of the body, and the contact between ball and bat (Stretch, Buys, Troit \& Viljoen, 1998). A batter uses FFD when facing a bowler who often delivers a full facing and accurate ball delivery to the stumpa or outside the stumps. The mechanisme for executing this technique is to use the upper hand with the bottom hand acting as a support below to ensure any sliding ball can be controlled. One basic technique often taught by cricket coaches when teaching FFD is for batters to lean their leading shoulder forward. In order to maintain balance, batters must bend their knees and at the same time maintaining head position so that the batter can step and move forward in equilibrium and confortably. In addition, body weight need to be transferred to the front leg by turning the waist forward and lifting the heel while maintaning balance (Australian Cricket Board, 2001; Woolmer \& Noakes, 2008).

Backlift technique in cricket is a key contributor to the success of batting for all skill levels (Noorbhai \& Noakes, 2016; Stuelcken, Portus, \& Mason, 2005). Stretch, Bartlett and Davids (2000), and, McLean and Reeder (2000) defined back lift technique as a technical element in batting for cricket which defies the traditional attempt to limit the motion in the linear phase. Based on the basics of cricket coaching, there is no clear reference to back lift orientation techniques whereby the position of the bat being in the horizontal plane is not relevant providing that the bat and the batter is in the correct position (Bradman, 1975; Woolmer \& Noakes, 2008). There are two types of back lift techniques used in cricket, namely back lift straight (BS) and back lift lateral (BL) techniques.

A study of 161 coaches worldwide showed that most coaches (83\%) train their players using the Back lift Straight (BS) technique instead of the Back lift Lateral (BL) technique (Noorbhai \& Noakes, 2018). The back lift straight technique usage is for a ball bowled in the middle of the stumps. However, the use of BS techniques has some disadvantages such as the batter is not positioned straight and close to the leg side. Generally most coaching manuals teach players to lift the bat towards the wicket-keeper or the bat is positioned in the middle of the stump in attempting to bat the ball (Noorbhai \& Noakes, 2016; The MCC, 1962).

However, cricket coaching manuals published after 2009 adopted the backlift lateral technique. Today many coaches adopted this technique by training their players to lift the bat to the position of the fielder on the slip side. Recent studies have shown that most successful players and uncoached cricketers (77\%) use backlift lateral techniques in batting (Noorbhai \& Noakes, 2016). On the other hand, coached cricketers use backlift straight techniques. Other studies also show that backlift lateral technique is one of the major contributing factor to successful batting (Noorbhai \& Noakes, 2016).

Research on the outcomes of the use of backlift straight and backlift lateral techniques is limited especially in Malaysia. Therefore, a study was conducted to determine if there are any differences in the use of the two backlift techniques. It has been noted that the use of these two techniques has positive impact on batters hitting technique. However, does the use of these two 
Vol. 8, No. 4, 2019, E-ISSN: 2226-6348 @ 2019 HRMARS

techniques improves players performance in terms of accuracy of hit, distance of hit and reaction time of batters? Therefore, this article seeks the answer the above question.

\section{Methodology}

Twenty two national cricket players were purposively selected to participate in this study. The basic criterion for selecting national cricket players is due to their exposure to both backlift techniques. Data for accuracy and reaction time were colected at the batting cage while data for distance were collected at the cricket oval. Data collection was aided by a bowling machine. A bowling machine was used to test front foot drive hit skills for both backlift straight and backlift lateral techniques. The use of a bowling machine aids in the consistency of speed of ball, thus allowing for some control for data collection technique.

Before conducting the test, respondents went through the warming up session to prepare their physiology ability for the testings. The warming up sesseion was conducted for 30 minutes including stretching of all muscles involve and also the cardiovascular system. This is done to reduce the risk of injury while doing the tests.

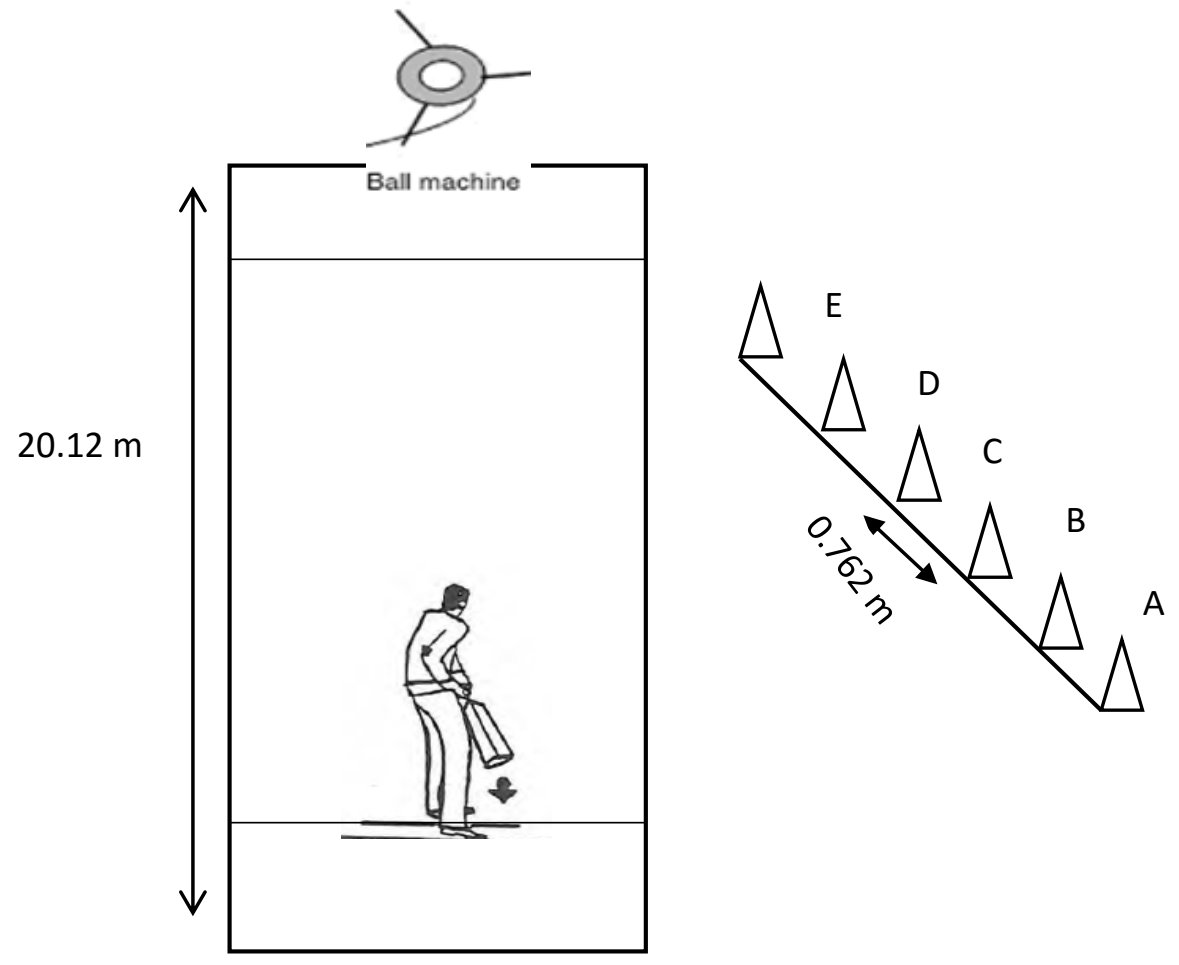

Figure 1: Set up for accuracy test

Testing for accuracy, distance and reaction time were conducted on different days. This is to allow the muscle to rest to avoid doing the test with exercise-induced fatigue withinin the muscles. On the first test day, upon completion of the warming up session, the respondents undergo a front foot drive batting test for accuracy. For the batting accuracy test, each respondent were bowl 10 balls and score were given based on where the ball goes. Figure 1 shows the set up for batting accuracy test. Five cones were arranged on the ground and each 
cone has different scores. If a batter hits the ball past cone A or E, 4 points is awarded. ! 0 points is awarded for batting to ball past cone $C$, while for batting past cones B or D the batter is awarded with 6 points. Batters used the directed back lift technique and bats using the front foot drive skill to the cones. Each batter were given 10 bowls and the maximum score a batter can obtain is 100 points. Batting away from the given area a zero score is given.

To test for distance, a big area is requires, thus this test was conducted at the cricket oval. The batter bats the ball bowled to him using the back lift technique indicated. The batter is free to choose to bat either leg side or off side. With good transfer mechanics the batter should be able to make long hits. Once a hit is made, the distance is measured. Figure 2 is an illustration of the hit to the leg side or off side.

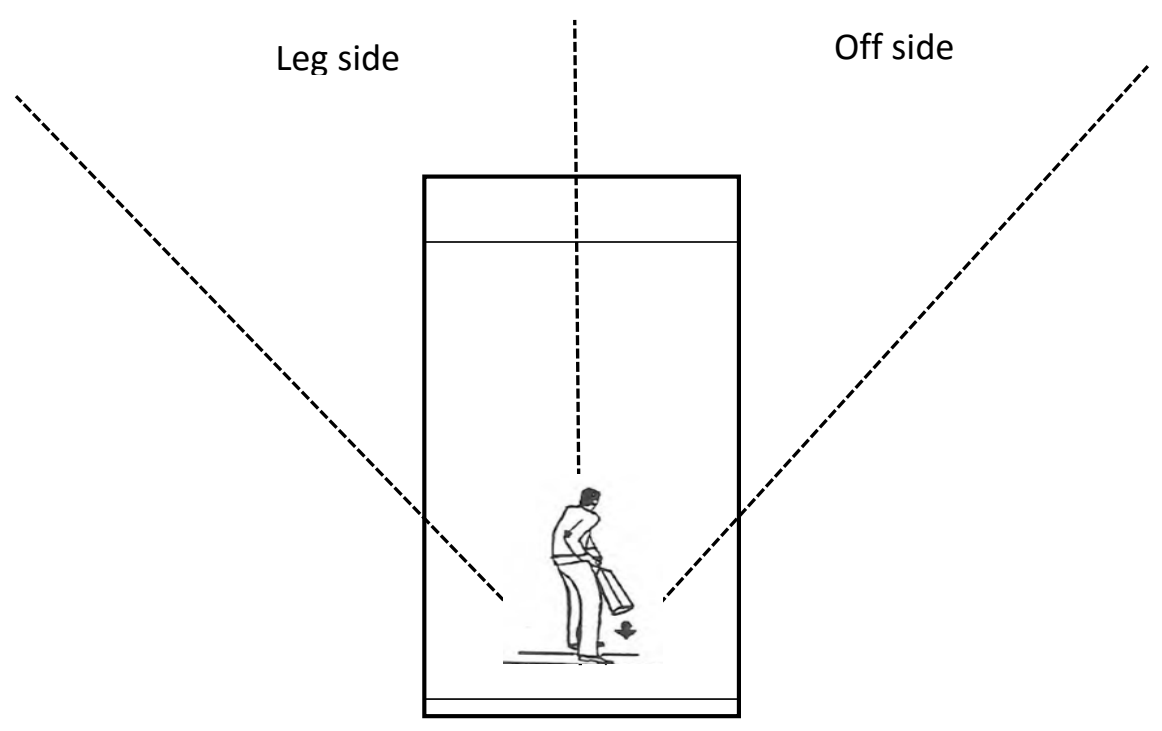

Figure 2: Set up for distance test

As for the reaction time test, the reaction time taken is between the first ball bounce and upon ball coming in contact with the bat. For research purposes, data from complete hits were taken into account. Figure 3 shows the positioning of the two cameras; one in front of the batter and the other is placed at the side of the batter. Camera 1 records the batter doing the front foot drive skill while camera 2 records the time between first bounce and ball coming in contact with the bat. Thus, the researcher will be able to correlate between the two backlift technique and reaction time. For this test, the batter needs to pay attention to the first ball bounce as this is important in improving their reaction time. All test sessions ended with cooling down activities to aid in recovery and avoid soreness due to accumulation of acid lactic especially to the main muscles used during the test. 


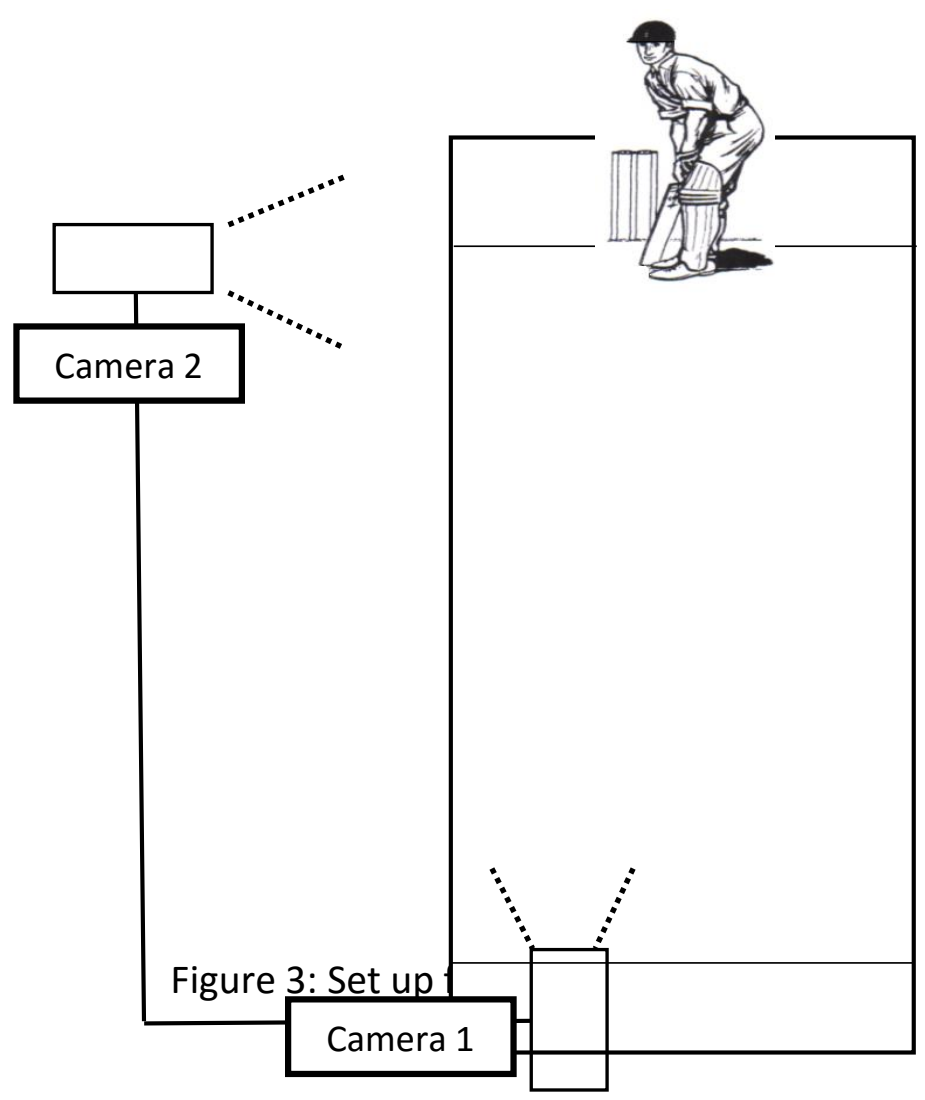

\section{Results}

Both descriptive and inferential statistics were used to analysed the data collected. Of the total number of samples, $77.3 \%$ were more than 22 years old of age and $50 \%$ of the samples has played cricket for more than 12 years. As for back lift skills, 63.6\% prefers back lift straight technique.

Table 1 Mean and standard deviation for accuracy, distance and reaction time for back lift lateral and back lift straight

\begin{tabular}{|l|c|c|c|}
\hline & Variables & Ristance & Reaction time \\
Types of Back lift & Accuracy & & \\
\hline Lateral & $63.45(3.912)$ & $43.21(5.136)$ & $0.5132(0.0631)$ \\
\hline Straight & $60.45(5.235)$ & $44.04(4.202)$ & $0.5027(0.0629)$ \\
\hline
\end{tabular}

Table 1 shows the mean and standard deviation for the back lift lateral and back lift straight techniques. For the back lift lateral group, the mean for accuracy is 63.45 (sd 3.912), mean for distance is 43.21 meters (sd 5.136) and mean for reaction time is 0.51 seconds (sd 0.063). For the back lift straight group, the mean for accuracy is 60.45 (sd 5.235), mean for distance is 44.04 meters (sd 4.202) and mean for reaction time is 0.50 seconds (sd 0.063). A t-test was conducted to determine if there is a significant difference between the two techniques of back lift on the 
Vol. 8, No. 4, 2019, E-ISSN: 2226-6348 @ 2019 HRMARS

variables tested. Table 2 shows the results of the t-test. There is a significant difference in hitting accuracy $(t=2.153, p=0.037)$ between back lift lateral and back lift straight techniques. However, there is no significant difference in distance hit $(t=-0.54, p=0.595)$ and reaction time $(t=0.55$, $\mathrm{p}=0.585)$.

Table 2: Results of t-test using different techniques of back lift in front foot drive batting skills

\begin{tabular}{llccccc}
\hline Variables & Groups & Mean & sd & $\mathbf{t}$ & $\mathbf{d f}$ & $\mathbf{p}$ \\
\hline Accuracy & Backlift Lateral & 63.45 & 3.912 & 2.153 & 42 & 0.037 \\
& Backlift Straight & 60.45 & 5.235 & & & \\
\hline Distance & Backlift Lateral & 43.28 & 5.136 & -0.535 & 42 & 0.595 \\
& Backlift Straight & 44.04 & 4.202 & & & \\
\hline $\begin{array}{l}\text { Reaction } \\
\text { time }\end{array}$ & Backlift Lateral & 0.5132 & 0.06312 & 0.550 & 42 & 0.585 \\
& Backlift Straight & 0.5027 & 0.06296 & & & \\
\hline
\end{tabular}

\section{Discussion}

Majority of the cricket players in this study is between the age of 22 to 25 years old. Cricket players in this age group showed matured skill ability compared to other age groups. This supports earlier researches that suggest older cricket players demonstrates better skills and playing techniques especially in predicting the direction of the ball in accordance to the type of pitch a bowler used. There is also a great variation in the number of years the sample is involved in playing cricket which is between 8 to 19 years of experience. Many of the cricket players in this sample played cricket at a very young age and many of them represented the country in age group competitions since they were still in primary school. This is because cricket is introduced to primary school children in Malaysia during physical education classes (Abdul Razak, 2017).

In this study, all samples do the same test for front foot drive hitting using both back lift straight and back lift lateral techniques. However, the players' preferences in using back lift straight or back lift lateral is equivalent, meaning $50 \%$ of the sample prefers back lift straight technique and the other $50 \%$ prefers back lift lateral technique.

The t-test analysis conducted on front foot drive hitting accuracy showed that there was significant difference between back lift straight and back lift lateral techniques. However, there were no significant differences for reaction time and distance hit. These results support finding of previous research (Noorbhai \& Noakes, 2019) whereby back lift lateral technique is the commonly used technique of hitting with front foot drive among amateur, professional and international cricket players. They also found out that international player that uses back lift lateral technique were more efficient in collecting runs for their teams as this technique contributes to highest run scores in a cricket game. In another study on 161 cricket coaches world wide, Noorbhai \& Noakes (2018) states that most coaches (83\%) train players by using the back 
lift straight technique instead of the back lift lateral technique (M. Noorbhai \& Noakes, 2018). Earlier study showed that successful international hitters in cricket uses the back Ift lateral technique as their preferred hitting technique (Noorbhai \& Noakes, 2016).

According Hinchliffe (2019), the best back lift is the lateral back lift as it allows the batter to hit the ball in various directions and at the same time saving for the batter to adjust holding technique to hit precisely to the target. Furthermore, back lift straight is a more superior whereby the batter can hit in any direction especially when facing a pace bowler.

On the other hand, back lift straight techniques has some shortcomings such as it limits the movement of the batter. Back lift straight technique allows the batter to focus his hit only on the leg side, thus ignoring the off side for his hitting direction. Hitting off side becomes difficult which may end up with the player more keen in executing cross batting. A batter who uses the back lift straight has a higher probability of hitting straight forward with a heavier bat to increase the power of his hit (Hinchliffe, 2019).

\section{Conclusion}

Results of this study showed that front foot drive hitting for accuracy is better when using the back lift lateral technique. However, further study need to be conducted to loof at the effectiveness of using this technique over a prolong period. This is especially for a game of cricket may span over a few hours to a few days at a time. Also, other factors such as the type of grip used, the stance of the batter and also the speed of the down swing are important variable that delimits this research. Therefore, future research should look at these variables as it may improved not only accuracy of hit but also may contribute to better distance hit and reaction time taken in response to the stimulus.

\section{Acknowledgement}

The study was supported by the grant from the Faculty of Education, Universiti Kebangsaan Malaysia, GG-2019-003.

\section{References}

Razak, A., Noruzzaman. (2017). Profil Penaakulan Pelajar Berdasarkan Permainan Kategori Jaring dan Dinding Dalam Pendidikan Jasmani., Universiti Pendidikan Sultan Idris, Perak. Retrieved from http://ir.upsi.edu.my/339/

Australian Cricket Board. (2001). Successful cricket coaching: the Aussie way. Australian Cricket Board, undated.

BBC Sport Cricket.). Master the Straight Drive. Retrieved August 3, 2019, from http://news.bbc.co.uk/sport2/hi/cricket/skills/4173904.stm

Bradman, Donald. (1975). The art of cricket: Rupa And Co; New Delhi.

Hinchliffe, D. (2019). Better cricker performance analysis. Retrieved October 19, 2019, from david25.com

Meng, K. Y., Zuhairi, N. A., Manan, F. A., Knight, V. F., Padri, M. N. A. \& Omar, R. (2015). Role of gender, age and ethnicities on visual reaction time and visual anticipation time of junior athletes in Australian Journal of Basic and Applied Science, 9(5), 129-134. 
McLean, S. P., \& Reeder, M. S. (2000). Upper extremity kinematics of dominant and nondominant side batting. Journal of Human Movement Studies, 38(4), 201-212.

Noorbhai, M. H., \& Noakes, T. D. (2016). A descriptive analysis of batting backlift techniques in cricket: Does the practice of elite cricketers follow the theory? Journal of sports sciences, 34(20), 1930-1940.

Noorbhai, M. H., \& Noakes, T. D. (2019). The lateral batting backlift technique: is it a contributing factor to success for professional cricket players at the highest level? South African Journal of Sports Medicine, 31(1), 1-9.

Noorbhai, M. H., \& Noakes, T. D. (2018). An evaluation of the coaching methods of the batting backlift technique in cricket. J Qual Res in Sports Stud, 12, 35-56.

Vision, P. (n.d.). How to exploit batting weaknesses: straight backlift. Retrieved August 7, 2019, from https://www.pitchvision.com/how-to-exploit-batting-weaknesses-straightbacklift\#/

Portus, M., Timms, S., Spratford, W., Morrison, N., \& Crowther, R. (2010). A batting skills test to assist the development of elite cricketeers, in Proceedings of Conference of Science, Medicine \& Coaching in Cricket, Brisbane, Australia. pp 125-129.

Raza, Ali, Diegel, Olaf, \& Arif, Khalid Mahmood. (2014). Robowler: Design and development of a cricket bowling machine ensuring ball seam position. Journal of Central South University, 21(11), 4142-4149.

Omar, R., Kuan, Y. M., Knight, V. F., Manan, F. A., \& Padri, M. N. A. (2017). Visual anticipation time difference between athletes in open and closed skills sports, in Movement, Health \& Exercise, 6(1), 13-19.

Stretch, R., Buys, F., Toit, E. D., \& Viljoen, G. (1998). Kinematics and kinetics of the drive off the front foot in cricket batting. Journal of Sports Sciences, 16(8), 711-720.

Stretch, R. A., Bartlett, R., \& Davids, K. (2000). A review of batting in men's cricket. Journal of Sports Sciences, 18(12), 931-949.

Stuelcken, M. C., Portus, M. R., \& Mason, B. R. (2005). Cricket: Off-side front foot drives in men's high performance Cricket. Sports Biomechanics, 4(1), 17-35.

The MCC. (1954). The M.C.C. cricket coaching book. London: William Heinemann Ltd.

The MCC. (1962). The MCC cricket coaching book: Revised and enlarged. The MCC cricket coaching book: Revised and enlarged: William Heinemann Ltd.

Woolmer, B. \& Noakes, T. (2008). Bob Woolmer's art and science of cricket: Struik Pub.

Kuan, Y. M., Zuhairi, N. A., Manan, F. A., Knight, V. F., \& Omar, R. (2018). Visual reaction time and visual anticipation time between athletes and non-athletes in Malaysian Journal of Public Health Medicine, Special Volume (1), pp 135-141. 